DOI: 10.12957/demetra.2018.30653

\title{
Determinação do teor de cafeína em diferentes tipos de cafés
}

\section{Determining caffeine content in different coffee types}

Cicero Jordan Rodrigues Sobreira da Silva' Cicero Jonas Rodrigues Benjamim² Luana Barreto Carvalho ${ }^{3}$ Elida Mara Braga Rocha ${ }^{4}$ Edna Mori ${ }^{3}$

' Faculdade de Juazeiro do Norte, Curso de Pós-graduação em Nutrição Esportiva. Juazeiro do Norte, CE, Brasil.

${ }^{2}$ Universidade de Pernambuco, Curso de Nutrição. Petrolina, PE, Brasil.

${ }^{3}$ Faculdade de Juazeiro do Norte, Curso de Nutriçã̃o. Juazeiro do Norte, CE, Brasil.

${ }^{4}$ Universidade de São Paulo, Faculdade de Saúde Pública, Pós-graduação em Nutrição em Saúde Pública. São Paulo, SP, Brasil.

Correspondência / Correspondence Cicero Jonas Rodrigues Benjamim E-mail: jonasbenjamlm@hotmail.com

\section{Resumo}

Buscou-se avaliar os teores de cafeína em diferentes marcas e tipos de cafés, analisando, determinando e comparando seus valores, verificando a conformidade com a legislação, e apontando se o tipo de processamento pode influenciar neste teor. Para a determinação de cafeína em cafés, adotou-se o método que envolve extração, separação, purificação e determinação por gravimetria. Para o referido estudo as amostras foram compostas por três marcas de café solúveis (Cs1, Cs2, Cs3), três marcas de cafés em pó (Cp1, Cp2, Cp3) e três marcas de cafés em grãos (Cg1, Cg2, Cg3) para análise dos teores adquiridos. De acordo com a Resolução CNNPA no12/1978, os cafés devem conter pelo menos $0,7 \%$ de cafeína em 100 gramas do produto. Foram encontradas, Cs1 0,36\%, Cs2 0,54\%, Cs3 0,56\%; Cp1 0,36\%, Cp2 0,39\%, Cp3 0,42\%; Cg1 0,48\%, Cg2 0,46\%\%, Cg3 0,46\%. Através das análises da determinação de cafeína nos diferentes tipos de cafés consumidos, foi possível observar que os teores variam em função da forma em que eles se apresentam (grão, pó e solúvel), sendo que a forma em café solúvel apresentou maior quantidade de cafeína do que o em grãos, seguido pelo em pó.

Palavras-chave: Bebidas. Café. Cafeína; Padrão de Identidade. Qualidade para Produtos e Serviços.

\section{Abstract}

The aim of the current study is to evaluate caffeine contents in different coffee brands and types by analyzing, determining and comparing their values, by checking their compliance with the 
legislation, and by indicating whether the processing type may influence caffeine content. The method encompassing extraction, separation, purification and gravimetric determination was herein adopted to help setting the caffeine contents in different coffee samples. These samples comprised three soluble coffee (Cs1, Cs2, Cs3), three coffee powder (Cp1, Cp2, Cp3) and three coffee bean brands (Cb1, Cb2, Cb3), which were subjected to content analysis. According to CNNPA Resolution n. 12/1978, coffee samples should present at least $0.7 \%$ caffeine per 100 grams of product. The herein analyzed samples recorded the following results: Cs1 (0.36\%), Cs2 (0.54\%), Cs3 (0.56\%); Cp1 (0.36\%), Cp2 (0.39\%), Cp3 (0.42\%); Cb1 (0.48\%), Cb2 (0.46\%) and Cb3 (0.46\%). The analysis applied to help determining the caffeine content in different coffee types showed that these contents changed depending on how the samples were presented (beans, powder and soluble). Results evidenced that the soluble coffee presented higher caffeine content than coffee beans, which were followed by coffee powder.

Keywords: Beverages. Coffee. Caffeine. Identity and Quality Standard. Products and Services.

\section{Introdução}

O café é um produto nobre do agronegócio e da pauta de exportação do Brasil, ocupando lugar de destaque na história do desenvolvimento do país. O sabor e aroma de sua bebida conferem grande receptividade a este produto, cujo consumo se tornou um hábito mundial. A indústria cafeeira emprega novas técnicas para a análise de seus produtos, aliados às técnicas de análises sensoriais já consolidadas, buscando inovações que atendem aos anseios do mercado europeu e do norte-americano. ${ }^{1}$

Atualmente, o café é a bebida mais consumida no Brasil e no mundo, visto que o aumento do seu consumo é cada vez maior, por ele apresentar substâncias que aceleram o metabolismo. ${ }^{2} \mathrm{O}$ produto é incluído nas dietas, para aumentar ainda mais o desempenho dos atletas e praticantes de atividades físicas.

Quando consumido em quantidades moderadas - em média até quatro xícaras por dia - torna o cérebro mais atento e capaz de suas atividades intelectuais; diminui a incidência de apatia e depressão; estimula a memória, a atenção e a concentração e, portanto, melhora a atividade intelectual, sendo adequado para todas as idades, inclusive crianças e adolescentes. ${ }^{3}$ 
O café apresenta mais de 800 compostos de várias classes já identificados, alguns dos quais muito citados na literatura por estarem associados com a saúde humana, destacando-se a cafeína que exerce uma elevação da pressão arterial, os diterpenos cafestol e kahweol, que podem acarretar distúrbios metabólicos como as dislipidemias, e os ácidos clorogênicos com a proteção contra a formação da placa ateromatosa. ${ }^{4}$

A cafeína é um composto químico de fórmula $\mathrm{C}_{8} \mathrm{H}_{10} \mathrm{~N}_{4} \mathrm{O}_{2}$, classificado como alcaloide do grupo das xantinas e designado quimicamente como 1,3,7-trimetilxantina. É encontrado em certas plantas e usado para o consumo em bebidas, na forma de infusão, como estimulante. ${ }^{5}$ É uma das substâncias mais conhecida presentes no café, apresentando também uma elevada atividade antioxidante, em virtude de seus efeitos metabólitos, que resulta do ácido 1-metilúrico e 1-metilxantina os quais têm efeito preventivo da oxidação da LDL, por atuar na peroxidação lipídica, sendo tal propriedade atribuída aos polifenóis resultantes do seu metabolismo. ${ }^{6}$

São vários os estudos que demonstram a relação entre o consumo de café e o risco de doença cardiovascular, sendo este um tema de muita discussão, ou seja, há estudos que mostram aumento de risco enquanto outros mostram redução. Entretanto, já se tem evidências demostrando que o café pode aumentar o risco de doença cardiovascular ocasionado pelo efeito agudo do consumo de café, especialmente relacionado ao seu componente cafeína. ${ }^{7}$

Dada a importância das reações que a cafeína exerce no organismo questiona-se: Quais os teores de cafeínas encontrados nos diferentes tipos de cafés e marcas disponíveis no mercado? As quantidades correspondem ao estabelecido pela legislação?

Pode-se supor que essa oscilação dos teores de cafeína nos diferentes tipos de cafés seria devido ao seu processamento, mas também por acréscimos de outros aditivos que não seja o café, bem como a espécie do grão e a sua forma de cultivo. As marcas, por serem obtidas de plantações e manejos diferentes, podem ocasionar quantidades de cafeína diferentes nos cafés. É sabido que a cafeína traz diversos benefícios para a saúde, quando ingerido em doses corretas, e como qualquer substância química, sua super dosagem pode gerar distúrbios e disfunções fisiológicas.

Além disso, sem a adequação correta desta substância em uma dieta, os efeitos negativos irão se mostrar presentes na rotina, principalmente se o indivíduo for atleta. O estado de alerta que a cafeína proporciona, irá reduzir o descanso metabólico necessário para que o organismo anabolize. A longo prazo os efeitos podem ser ainda maiores, o que mostra claramente a importância do conhecimento de quantidade de cafeína nos cafés, que é uma das bebidas mais consumidas no mundo.

Diante do exposto, buscou-se avaliar os teores de cafeína em diferentes marcas e tipos de cafés, analisando, determinando e comparando seus valores, verificando a conformidade com a legislação, e apontando se o tipo de processamento pode influenciar neste teor. 


\section{Metodologia}

A pesquisa é um estudo experimental, quantitativo e comparativo, realizada com cafés de diferentes tipos e marcas. O estudo foi realizado durante o mês de maio do ano de 2017, no laboratório de química da Faculdade de Juazeiro do Norte, localizada na cidade de Juazeiro do Norte, interior do Ceará, situada na área central da Região Metropolitana do Cariri, no sul do estado.

Para avaliar o teor de cafeína adotou-se o método descrito por Foguel; Calderini \& Aristaque. ${ }^{8}$ $\mathrm{O}$ método de escolha foi do tipo aleatório. As amostras foram adquiridas por compra em supermercados locais e compra pela internet, e encaminhadas para o laboratório. onde foram preparadas para análise. Foram avaliadas 3 marcas para cada forma de apresentação de café (solúvel, em pó e em grão) contidos em embalagens de 250 e 500g, a saber: café solúvel 1 (CS1); café solúvel 2 (CS2); café solúvel 3 (CS3); café em pó 1 (CP1); café em pó 2 (CP2); café em pó 3 (CP3); café em grão 1 (CG1); café em grão 2 (CG2); café em grão 3 (CG3), perfazendo um total de 9 amostras, sendo que as análises destas amostras foram realizadas em triplicata totalizando 27 experimentos.

Para avaliar o teor de cafeína foram desenvolvidas as seguintes etapas: extração da cafeína com ácido sulfúrico, purificação com clorofórmio e caracterização com isopropanol e hexano. A quantificação de cafeína nos diferentes tipos de cafés foi efetuada por gravimetria.

Os dados foram tabulados utilizando uma planilha do Microsoft Office Excel 2010, gerando tabelas e gráficos, empregando o desvio padrão simples com significância de 5\% para definição dos resultados através dos valores médios.

Para a interpretação dos dados foi realizado um estudo comparativo entre as diferentes formas de apresentação de café (grão, pó e solúvel) a fim de verificar se o processamento influi no seu teor, e, ainda, os valores encontrados foram confrontados com dados de literatura e analisado com o permitido pela legislação.

\section{Resultados}

Após a análise, pode-se perceber que dentre os tipos de café o solúvel foi o que apresentou maior percentual médio de cafeína em comparação ao café em grãos e em pó (Tabela 1). 
Tabela 1. Teor de cafeína encontrado nas diferentes marcas e tipos de cafés analisados em triplicatas. Juazeiro do Norte, CE. 2017.

\begin{tabular}{lccc}
\hline Variável & $\mathbf{n}$ & Média $(\%)$ & Desvio Padrão \\
\hline Café solúvel & 3 & 0,486 & 0,110 \\
Café em pó & 3 & 0,390 & 0,030 \\
Café em grãos & 3 & 0,466 & 0,011 \\
\hline
\end{tabular}

$\mathrm{n}=$ número de marcas analisadas de cada tipo de café.

Destaca-se que os tipos de café apresentaram diferentes variações no teor de cafeína. Entre as marcas coletadas o café solúvel tinha maior variação no teor de cafeína (0,36\% - 0,56\%), e o café em grãos a menor $(0,46 \%$ - 0,48\%).

\section{Discussão}

A falta de informação nos rótulos sobre a quantidade de cafeína existente nos cafés remete à dificuldade na adequação de dietas, podendo expor a saúde do indivíduo a efeitos negativos, devido aos seus efeitos psicoativos, que, em excesso, pode gerar uma disfunção fisiológica no organismo.

Uma das explicações para essa falta de informação na rotulagem poderia estar relacionada à possibilidade de mistura dos grãos de várias espécies sem a devida determinação de quantidade, já que o teor de cafeína pode variar de acordo com a espécie. Também, pela falta de normas que obriguem as indústrias cafeeiras à divulgação da quantidade, pois a Agência Nacional de Vigilância Sanitária - ANVISA apenas determina o mínimo que deve conter.

Com base nos resultados, nenhum dos cafés analisados estava de acordo com a resolução CNNPA - Comissão Nacional de Normas e Padrões para Alimentos nํ12/1978, visto que ela determina que deve conter pelo menos $0,7 \%$ de cafeína em 100 gramas do produto apresentado na forma de pó e os teores encontrados foram inferiores ao preconizado. ${ }^{9}$

Quando observado cada tipo de café separado, visando comparar o teor de cafeína em diferentes marcas, é possível observar uma significativa variação quantitativa existente entre as marcas analisadas, que pode remeter aos processos existentes antes do consumo, ou até mesmo em processos de plantio e colheita como supracitado.

Nesse contexto, no estudo de Nogueira \& Trugo, ${ }^{4}$ a composição do café variou dependendo das condições do processamento, das espécies e variedades utilizadas nas misturas de cada fabricante sendo que a quantidade de cafeína pode ser diferente mesmo utilizando-se pó do mesmo fabricante. 
Segundo os autores, com relação às espécies, o café Robusta apresenta maiores teores de cafeína e ácidos clorogênicos e menores de trigonelina do que o café Arábica. Assim, a participação de cada uma dessas espécies utilizadas pelo fabricante e as condições do processo serão determinantes da composição final do café.

É possível observar uma pequena variação entre os diferentes tipos de cafés, onde os cafés solúveis apresentaram teor maior de cafeína que os demais tipos, seguidos pelos cafés em grãos e, posteriormente os cafés em pós.

Os teores de cafeína de grãos crus de diferentes linhagens podem variar em função do local do cultivo, origem genética e entre épocas de colheita, devido às diferenças no grau de maturação dos frutos. ${ }^{10}$

As diferenças entre os teores de cafeína nos dois tipos de café (pó e instantâneo) talvez existam por uma possível variedade de grãos utilizados em suas formulações. O conteúdo de cafeína nas sementes da espécie Robusta é maior do que nas sementes do Arábica e, de acordo com o mesmo autor, o primeiro é geralmente usado na fabricação de café instantâneo enquanto que o último na obtenção de café em pó torrado. ${ }^{11}$

A relação entre o consumo de cafeína e o possível desenvolvimento de algumas doenças tem despertado há muito tempo o interesse de cientistas. Apesar de não existirem evidências de que a ingestão de cafeína em doses moderadas ( $\sim 300 \mathrm{mg} /$ dia) sejam prejudiciais à saúde de um indivíduo normal, esta substância vem sendo continuamente estudada pois ainda persistem muitas dúvidas e controvérsias quanto aos seus efeitos adversos na saúde. ${ }^{12}$ Já o seu consumo em grandes doses, produz excitação, ansiedade e insônia, ainda assim, consumidores habituais desenvolvem uma certa tolerância aos efeitos desse composto, visto que, gradativamente, aumentam o consumo para obtenção de efeitos iniciais. ${ }^{13}$

Dentre as diversas modalidades e práticas esportivas, a cafeína vem sendo aplicada como instrumento de pesquisa nos mais diversos estudos, como intenção de aumento do desempenho físico.

Algumas evidências mostram que a suplementação com cafeína não melhora a performance da força muscular máxima, enquanto outros têm relatado resultados positivos de melhor desempenho após a ingestão de cafeína, o bastante para tornar a sua suplementação amplamente difundida no meio esportivo. ${ }^{14-16}$ Dentre os diversos exercícios aeróbicos, estudos mostraram que a cafeína pode melhorar o desempenho físico em práticas como: corrida, ${ }^{17}$ ciclismo, ${ }^{18,19}$ remo $^{20}$ e até mesmo no futebol. ${ }^{21}$

O efeito ergogênico da cafeína sobre a performance em treino de força muscular ainda não está plenamente estabelecido, nem tampouco os mecanismos de ação fisiológica sobre o organismo. ${ }^{14}$ Por outro lado, em concordância com os resultados encontrados, outros autores têm demonstrado melhoras na performance de força muscular. ${ }^{16}$ 
O campo esportivo tem desenvolvido muitas pesquisas com esse componente e pode-se perceber que é uma área que apresenta muitas controvérsias nos seus achados. ${ }^{13}$

\section{Conclusão}

Pelos resultados encontrados foi possível observar uma variação existente em relação ao teor de cafeína, sendo que a forma em café solúvel $(0,486 \%)$ apresenta maior quantidade de cafeína do que em grãos $(0,466 \%)$, seguido pelo café em pó (0,360\%). Com isto, pode-se afirmar que as quantidades de cafeína em preparações variam com a forma de apresentação, quantidade utilizada, espécie/variedade/blend e o tipo de cultivo do café.

\section{Colaboradores}

Benjamim CJR e Rocha EMB trabalharam na interpretação de dados, revisão do artigo e aprovação da versão final; Carvalho LB participou da coleta de dados; Mori E e Silva CJRS trabalharam na coleta de dados e desenvolvimento da escrita do estudo.

Conflitos de interesses: Os autores declaram que não haver conflito de interesses.

\section{Referências}

1. Rocha EMP, Ferreira MAT. Análise dos indicadores de inovação tecnológica no Brasil: comparação entre um grupo de empresas privatizadas e o grupo geral de empresas. Ciência e Informação. 2001; 30(2):64-69.

2. Associação Brasileira da Indústria e Café [Internet]. [acesso em: 18 jul. 2016]. Disponível em: www. abic.com.br

3. Café e composição química [Internet]. ABIC- Associação Brasileira da Indústria e Café. [acesso em: jul. 2016]. Disponível em: http://www.abic. com.br/café_composiçãoquimica.html

4. Nogueira M, Trugo LC. Distribuição de isômeros de ácido clorogênico e teores de cafeína e trigonelina em cafés solúveis brasileiros. Ciência e Tecnologia dos Alimentos. 2003; 23(2):296-299.

5. Fernandes C, Monteiro, S. Viagem gastronômica através do Brasil. $7^{\mathrm{a}}$ ed. São Paulo: Editora Senac; 2005.

6. Dórea JG, Costa THM. Is coffee a functional food? BJN. 2005; 93(6):773-782.

7. Melo PG, Andrade APS, , Aquino FJT, Morais SAL, Chang R, Santos DQ, et al. Avaliação do potencial alelopático e efeitos fitoquímicos obtidos da casca de café (Coffea arabica). XXXII Reunião Anual da Sociedade Brasileira de Química; 30 maio-02 jun. 2009; Fortaleza. Anais... Sociedade Brasileira de Química. [acesso em: 15 maio 2017]. Disponível em: http://sec.sbq.org.br/cdrom/32ra/resumos/ T1349-2.pdf 
8. Foguel AF, Calderini MS, Aristaque MF. Estudo comparativo entre os teores de cafeína presente nos diferentes tipos de cafés industrializados. São Paulo: UNIARARAS; 2010.

9. Brasil. Resolução - CNNPA n 12, de 1978. Padrões de Identidade e Qualidade de alimentos e bebidas. Diário Oficial da União. 24 jul. 1978.

10. Pimenta CJ. Qualidade do café (Coffea arabica L.) originado de frutos colhidos de quatro estádios de maturação [dissertação]. [Lavras]: Universidade Federal de Lavras, Programa de Pós-Graduação em Ciência dos Alimentos; 1995.

11. Jacobs I, Pasternak H, Bell DG. Effects of ephedrine, caffeine, and their combination on muscular endurance. Med Sc Sports Exerc. 2003; 35(6):987-994.

12. Institute of Food Technologists. Evaluation of caffeine safety. Food Technology. 1988; 40(3):106-115.

13. Guerra RO, Bernardo GC, Gutiérrez CV. Cafeína e esporte. Rev Bras Med Esporte. 2004; 6(2):60-62.

14. Altimari LR. Ingestão de cafeína como estratégia ergogênica no esporte: substância proibida ou permitida? "Carta ao Editor". Rev Bras Med Esporte. 2010; 16(4):314.

15. Burke LM. Caffeine and sports performance. Appl Physiol Nutr Metab. 2008; 33(6):1319-1334.

16. Goldstein ER, Jacobs PL, Whitehurst M, Penhollow T, Antonio J. Caffeine enhances upper body strength in resistancetrained women. J Int Soc Sports Nutr. 2010; 7:18.

17. Imagawa TF, Hirano I, Utsuki K, Horie M, Naka A, Matsumoto K, et al. Caffeine and taurine enhance endurance performance. International J Sports Medic. 2009; 30(7):485-488.

18. Goldstein ER, Ziegenfuss T, Kalman D, Kreider R, Campbell B, Wilborn C, et al. International Society of Sports Nutrition position stand: Caffeine and performance. J Int Soc Sports Nutr. 2010; 7(1):5.

19. Simmonds MJ, Mihahan CL, Sabapathy S. Caffeine improves supramaximal cycling but not the rate of anaerobic energy release. Eur J Appl Physiol. 2010; 109(2):287-295.

20. Skinner TL, Jenkins DG, Coombes JS, Taaffe SR, Leveritt MD. Dose response of caffeine on 2000$\mathrm{m}$ rowing performance. Med Sci Sport Exerc. 2010; 42(3):571-576.

21. Foskett A, Ali A, Gant N. Caffeine enhances cognitive function and skill performance during simulated soccer activity. Int J Sport Nutr Exerc Met. 2009; 19(4):410-423.

Recebido: 02 de outubro de 2017

Revisado: 04 de maio de 2018

Aceito: 08 de junho de 2018 